\title{
Global Harmonic Rate Assessment in the Electricity Distribution Network in Niamey City: Case Studies of Domestic, Industrial and Hospital Substations
}

\author{
Abdourahimoun Daouda1, Saïdou Madougou1 ${ }^{*}$, Abdoul Aziz Ibrahim² \\ ${ }^{1}$ Laboratoire d'Energétique, d'Electronique, d'Electrotechnique, d'Automatique et d'Informatique Industrielle, \\ Université Abdou Moumouni, Niamey, Niger \\ ${ }^{2}$ Société Nigérienne d'Electricité (NIGELEC), Niamey, Niger \\ Email: *nassara01@yahoo.fr, daoudaabdourahimoun@gmail.com
}

How to cite this paper: Daouda, A., Madougou, S. and Ibrahim, A.A. (2017) Global Harmonic Rate Assessment in the Electricity Distribution Network in Niamey City: Case Studies of Domestic, Industrial and Hospital Substations. Energy and Power Engineering, 9, 786-801.

https://doi.org/10.4236/epe.2017.912049

Received: August 20, 2017

Accepted: November 19, 2017

Published: November 22, 2017

Copyright (c) 2017 by authors and Scientific Research Publishing Inc. This work is licensed under the Creative Commons Attribution International License (CC BY 4.0).

http://creativecommons.org/licenses/by/4.0/

\begin{abstract}
Like others countries of the world, in Niger also, we are witnessing an increasing use of non-linear electric loads in the domestic, hospital and industrial sectors. However, these loads degrade the shape of the electrical signal and cause disastrous effects to the equipment of the distribution system and the devices which are connected to the network. This article highlights the presence of electric harmonics in the distribution network in Niamey city. In order to do this, measurements were taken at the secondary level of the substations using an energy quality analyze $r$ (FLUKE 1735). By using this measuring instrument, we quantified the voltage and current Total Harmonic Distortion (THD) in the three substations. The results obtained show that, although the statutable rates set by the standards are not exceeded for phase conductors, the neutral contains a very critical percentage of distortion on the residential and hospital substations. Moreover, this assessment made it possible to observe the variation of harmonics in the presence of voltage drops.
\end{abstract}

\section{Keywords}

Electric Power Distribution Network, Harmonic Disturbance, Total Harmonic Distortion (THD), Power Quality, Distribution Network

\section{Introduction}

In Africa, the issue of electricity access is at the center of the development challenge. In fact, many African countries have a small electricity distribution net- 
works and mainly in the form of islands [1]. Niger's electricity distribution network meets these technical criteria. Despite its power potentialities, Niger is still in a situation of dependence on electricity, with only one electricity company (called NIGELEC).

Hence the electricity subsector is characterized in 2015 by low access and coverage rate (respectively $10.65 \%$ and $27.34 \%$ ) [2], the inadequate and aging of the power generation, transmission and distribution, poor quality of service, inadequate tariffs and insufficiency of regulation in this subsector [3]. We are witnessing in Niger a significant use of non-linear loads in almost all sectors of activity (domestic, hospital, industrial, etc.), among which we can easily quote: economical light bulbs, screen televisions, computers, mobile phone chargers, etc.

In addition, the West African Economic and Monetary Union (WAEMU) launched in Niger a power efficiency project in April 2011, with the aim of reducing electricity consumption, therefore, increasing energy availability.

The main objective of this project is to replace the power consuming loads to the low consumption loads. This improvement in energy efficiency is to the detriment of the quality of the energy since even if it is supplied with a sinusoidal voltage, the current absorbed is not [4].

The distribution of high quality electricity is one of the objectives of any electricity supplier. But, the quality of electricity is a complex and diversified subject because it requires a good dimensioning of all the components of the electrical chain and a monitoring of the characteristics of the electrical signal. In order to improve energy efficiency and the quality of electrical energy for sustainable development, electricity companies in industrialized countries often carry out measurements of electrical harmonics [5] [6]. These allow them to assess the presence of harmonic disturbances and to predict its evolution over time. It is known that electrical equipments of industrial, tertiary and domestic area inject harmonic current in the distribution networks [7]. This work, the first of its kind in Niger, presents a study of the harmonic disturbances in the electricity distribution network of Niamey city, in order to assess the overall harmonic rate of these disturbances. Given the nature of the electrical loads encountered in Niamey city, three types of separate items were investigated including:

- one (01) hospital substation: Lamorde National Hospital;

- one (01) domestic substation: Kalley-East substation;

- one (01) industrial substation: ORIBA substation.

In this work, we first introduce the theory of electrical harmonics, followed by a description of materials and methods used, and finish with the presentation, analysis and interpretation of the results.

\section{Theory of Electrical Harmonics}

In the distribution system, the quality of service in electricity consists in guaranteeing the characteristics of the voltage to be supplied to the subscribers. Those are: amplitude, frequency, wave form and symmetry. However this electricity is 
subject to several deformations, either from the supplier's activities or caused by customer loads. Of all the existing disturbances, the harmonics are the most permanent because they are generated by the loads (Televisions, fans, energy efficient light bulbs, variable speed drives, computer devices and hospital device sect.). They distort the current and voltage and cause disastrous effects on the components of the network, i.e., electrical generators, cables, transformers, circuit breakers, etc., and connected devices through their premature termination. It is:

- overheating of distribution cables;

- shutdown of circuit breakers;

- Loss of Neutral and Premature Ageing of substation;

- Premature failure and shutdown of equipments connected to the distribution network.

\subsection{Definition of Electrical Harmonics}

The electrical harmonics are sinusoidal signals having frequencies that are all multiples of the frequency at which the supply system is designed to operate. These signals will add to the fundamental signal to give a disturbed signal.

\subsection{Quantization Quantities of Harmonics}

\subsubsection{Mathematical Tools}

Joseph Fourier was the first to find a way to decompose a periodic signal called Fourier transform. There are several forms of Fourier transforms to decompose a signal, and the discrete Fourier transform (DFT) is the one suitable for signal analysis. The DFT highlights the frequency spectrum. However another transform, more practical than the DFT, was discovered by Cooley and Turkey in 1965. It is: the Fast Fourier Transform (FFT). Like the DFT, the FFT allows to identify the harmonics but in a faster way than the other.

\subsubsection{Fourier's Series of a Periodic Signal}

Let $y(t)$ be a periodic function of $T$ satisfying the condition of Dirichlet [8]. The Fourier series of this signal is [8]:

$$
Y(t)=Y_{0}+\sum_{N=1}^{N=\infty} Y_{n} \sqrt{2} \cos \left(n w t+\varphi_{n}\right)
$$

With: $W=2 * p i * f ; Y_{0}$ : a constant function; $Y_{1}$ : the fundamental function and $Y_{n} \geq 2$ : the harmonic functions.

\subsubsection{Discrete Fourier Transform}

The Discrete Fourier Transform (DFT) is a rigorous way of calculating the Fourier transform of a signal that is both periodic and discrete [9]. The use of a $D F T$ for the analysis of a harmonic signal makes it possible to have an estimate of the value of its Fourier transform on $\mathrm{N}$ points. However, in digital applications, an algorithm based on this transform is used. Thus the mathematical expression of the Discrete Fourier Transform is [10]: 


$$
Y_{D F T}(k)=\sum_{n=0}^{N-1} y(n) \mathrm{e}^{-j 2 \prod n k / N}
$$

With, $Y(n)$ is the coefficients of the Fourier series; $N=\frac{T}{F_{e}}$, the number of points or sampling and $N$ and k non-zero integers.

Where $T$ is the period and $F_{e}$ the sampling frequency

Moreover, reconstruction is possible. This reconstruction is commonly called discrete inverse Fourier transform. It is calculated as follows [10]:

$$
Y[n]=\frac{1}{N} \cdot \sum_{k=9}^{N-1} Y_{D F T}[k] \mathrm{e}^{j 2 \prod n k / N}
$$

\subsection{Electrical Quantities for a Distorted Signal}

The determination of the three instantaneous powers also makes it possible to detect the electrical harmonics. Hence they need to be able to retain the formulas of electrical quantities and its derivatives.

\subsubsection{Apparent Power}

The apparent power is a dimensioning factor of equipment; it is expressed as follows [11]:

$$
S^{2}=P^{2}+Q^{2}+D^{2}
$$

Where $D$ is the deforming power (VAD), $P$ is the real power and $Q$ is the reactive power.

It is important to retain that the apparent power of a linear signal is different from that of the non-linear signal.

\subsubsection{Power Factor}

It is an electrical parameter defining the level of quality of the power consumed. It is determined in the presence of non-linear charges by the following equation [11]:

$$
P F=\frac{P}{S}
$$

where: $P$ is the real power and $S$ is the total apparent power (fundamental + harmonic components).

\subsection{Quantification of Harmonics}

\subsubsection{Harmonic Row}

The row of the harmonics is the ratio of the frequency of the harmonic $\left(f_{n}\right)$ to the frequency of the referential or fundamental sinusoidal function $\left(f_{1}\right)$. It is written as follows [11]:

$$
N=\frac{f_{n}}{f_{1}}
$$

\subsubsection{RMS Value of the Harmonic Magnitude}

For a deformed magnitude, and in steady state, the energy dissipated by the 
Joule effect is the sum of the energies dissipated by each of the harmonic components [12]:

$$
Y=\sqrt{\sum_{n=1}^{N=\infty}\left(Y_{n}^{2}\right)}
$$

\subsubsection{Distortion Rate}

This quantity allows us to detect polluted networks of harmonics. It can be determined with the harmonic distortion rate according to the definition given by IEC which referred to as harmonic distortion or distortion factor. The harmonic content can be calculated either with:

\section{- The Overall Harmonic Distortion Rate}

It represents the ratio of the effective value of the harmonics $Y_{n}$ to the effective value of the fundamental $Y_{1}[13]$.

$$
\operatorname{THD}(\%)=100 \frac{\sqrt{\sum_{n=2}^{n=\infty} Y_{n}^{2}}}{Y_{1}}
$$

where, $Y_{n}$ is the RMS value of $(n-1)$ electrical harmonics and $Y_{1}$ is the effective value of the fundamental.

\section{- The Individual Harmonic Distortion Rate}

It is calculated with the ratio of the effective value of the harmonic of rank $\boldsymbol{n}$ on the effective magnitude of the fundamental [13].

$$
\operatorname{THDI}(\%)=100 \frac{Y_{n}}{Y_{1}}
$$

\subsubsection{Standards}

For the proper functioning of the electrical system, standards have been established by the related institutions. Indeed IEEE and IEC set the criteria of a qualitative electricity product and they have several series according to the problems and the fields of application. In each of the standards, there are several series according to the targeted disturbances and the levels of the electrical network.

For the low voltage network, contractual values have been set by IEEE to prevent the effects of harmonic disturbances.

\section{1) The Harmonic voltage ratio}

The overall permissible harmonic content of the harmonics was set at $5 \%$ according to IEEE Std 519-1992. Moreover, this same standard specifies that the harmonic rate varies according to the field of application:

- $3 \%$ for the hospital sector, airport etc;

- $5 \%$ for the general sector;

- and $8 \%$ for the sector with AFDs.

On the other hand, a new examination of the 519 norms was operated in 2014. This examination has modified and increased the voltage rate from $5 \%$ to $8 \%$ for a low voltage system: $\mathrm{V} \leq 1 \mathrm{kV}$ [14].

\section{2) The harmonic current rate}

Non-linear loads inject harmonics into the electrical system. In order for this 
network not to be polluted, it is necessary to respect the values set by the standards. It is in this sense that IEEE 519-1992 established acceptable contract values as set out in Table 1 . In a distribution network, the harmonic rate injected by the loads is calculated as follows [13]:

$$
\operatorname{TDD}(\%)=100 \frac{\sqrt{\sum_{n=2}^{n=\infty} I_{n}^{2}}}{I_{L}}
$$

In Equation (10), $I_{L}$ represents the value of the maximum current recorded during the recording and $I_{n}$ is the RMS value of $(n-1)$ harmonics.

\section{Materials and Methods}

\subsection{Measuring Device}

The measuring instrument we used is FLUKE 1735. This device is an electrical network analyzer, and it allows recording all the electrical quantities (current, voltage, frequency, etc.). Figure 1 presents the electric network analyzer that we used.

The network analysis instrument of Figure 1 has limit values which are summarized in Table 2.

\subsection{Connection Point of the Analyzer to Electrical Network}

The point of measurement is very delicate in the analysis of the network. IEEE defines this point as being the node that can serve any customer [14]. The secondary part of the transformers HTA/BT of distribution is the appropriate point of use, to assess the presence of harmonics in an electrical distribution network [11]. Figure 2 illustrates exactly the connection point of the analyzer.

\subsection{Setting the Analyzer}

Before connecting the analyzer for continuous recording to each of the above substations, it is important to configure the analyzer according to the characteristics of the substations and the aggregation time chosen. Below are the different steps in our case:

Table 1. Harmonic current limits of a distribution system from $120 \mathrm{~V}$ to $69 \mathrm{kV}$ (Source: translation IEEE Std 519-1992).

\begin{tabular}{ccccccc}
\hline \multicolumn{7}{c}{$\begin{array}{c}\text { Maximum harmonic current as a percentage of IL } \\
\text { Individual harmonic rank (odd rank) }\end{array}$} \\
\hline$I_{s d} I_{L}$ & $<11$ & $11 \leq \mathrm{h} \leq 17$ & $17 \leq \mathrm{h} \leq 23$ & $23 \leq \mathrm{h} \leq 35$ & $35 \leq \mathrm{h}$ & TDD \\
\hline$<20$ & 4 & 2 & 1.5 & 0.6 & 0.3 & 5 \\
$20<50$ & 7 & 3.5 & 2.5 & 1 & 0.5 & 8 \\
$50<100$ & 10 & 4.5 & 4 & 2 & 0.7 & 12 \\
$100<1000$ & 12 & 5.5 & 5 & 2.5 & 1.4 & 20 \\
$1000<$ & 15 & 7 & 6 & 2.5 & 15 \\
\hline
\end{tabular}

In Table $1, I_{s c}$ is the maximum short-circuit current and $\mathrm{h}$ is meaning the harmonic row. 
Table 2. Specifications of FLUKE 1735.

\begin{tabular}{ccc}
\hline Magnitude & Values & Measurement error \\
\hline Effective voltage & $\begin{array}{c}\text { Measurement range in Star: } 57 \text { to } 480 \mathrm{~V} \\
\text { Measuring range in delta: } 100 \text { to } 830 \mathrm{~V}\end{array}$ & $\pm 0.5 \%$ \\
Current & Measuring Game Flex Kit: $3000 \mathrm{~A}$ & $\pm 0.5 \%$ \\
Frequency & Measuring Game: 46 to 54 and 56 to $64 \mathrm{~Hz}$ & $\pm 0.5 \%$ \\
THD & Up to the $50^{\text {th }}$ harmonic & $<0.15 \%$ (for V) \\
Power factor & 0.000 to 1.000 & $<0.5 \%$ (for I) \\
Sampling frequency & $10240 \mathrm{~Hz}$ & $\pm 1 \%$ \\
\hline
\end{tabular}

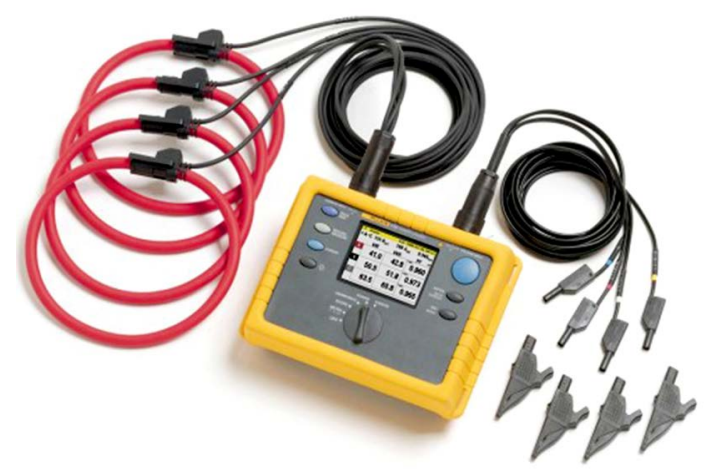

Figure 1. Overview of the 1735 analyzer.

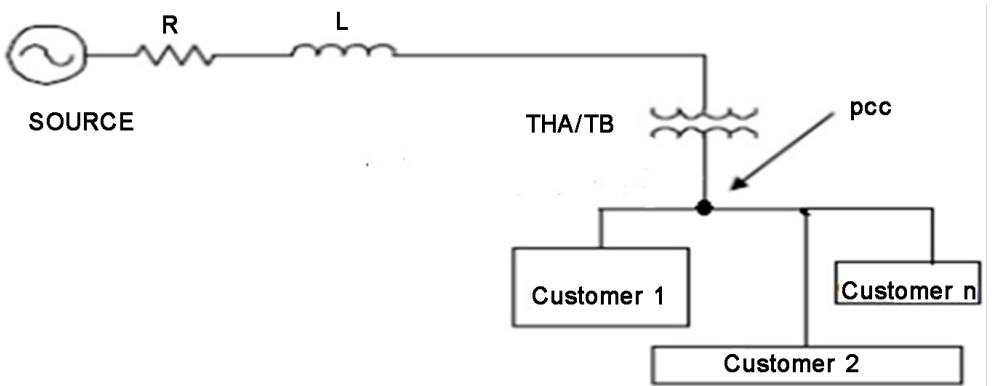

Figure 2. Synoptic diagram of the distribution network.

- Step 1: Record in medium mode; Recording interval of $1 \mathrm{mn} 40 \mathrm{~s}$.

- Step 2: power of the Network:

Network topology: Star;

Nominal voltage: $230 \mathrm{~V}$;

Frequency: $50 \mathrm{~Hz}$.

- Step 3: Setting the date and time;

- Step 4: Setting the cursor to harmonic mode.

\subsection{Connecting the Analyzer}

Figure 3 shows (a) the circuit diagram of the analyzer on the substations, (b) the analyzer connected to the industrial site during a measurement session. 


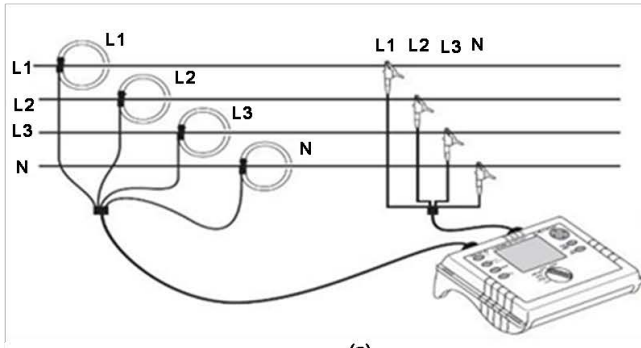

(a)

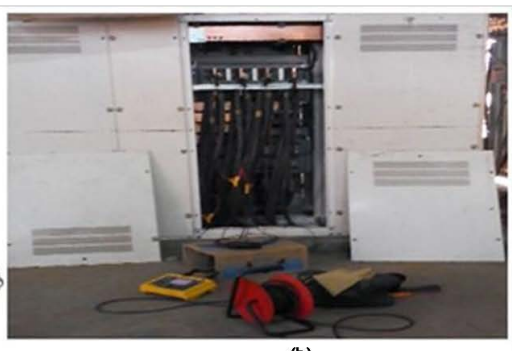

(b)

Figure 3. (a) Connection of the analyzer to the substations; (b) measurement substations illustration: industrial substations.

\subsection{Measurement Sites}

The distribution network of Niamey city has about 1100 electrical substations. They are composed of subscriber, private and mixed stations. The distribution line to the transformers is three-phase (without neutral distributed). All cabin stations (apparent power greater than or equal to $250 \mathrm{kVA}$ ) are coupled in delta/star (transformer HV/LV) for the supply of subscribers. Considering the nature of the electrical loads encountered in Niamey city, three types of the electrical substations were investigated. It is about a hospital transformer (National Hospital of Lamorde, HNL), a domestic transformer (Kalley-East post) and an industrial transformer (ORIBA post). The electrical characteristics recorded on the nameplates on the three transformers exploited are specified in Table 3.

\subsection{Measurement Data}

The analyzer is accompanied by its software for the recovery and processing of recorded data. After installing the software on the PC, the analyzer is connected to the computer following the procedures listed below to recover the data:

- Switch on the analyzer;

- Click on the shortcut of the software;

- Click on download or the data transfer from the analyzer to the PC (usually in FPQ format).

Figure 4 describes a data view recorded on the hospital substation.

On the screenshot of Figure 4, there are window tabs allowing presenting this data in scope or table form, etc. In addition to the data storage options of the device memory, they are transferable on spreadsheet software for future operation.

\section{Presentation, Analysis and Interpretation of the Results}

\subsection{Presentation of Results}

\subsubsection{Results of the Residential Site}

Figure 5 shows the evolution of the consumption in 24 hours on the residential substation.

Figure 6 shows the variation of the overall harmonic rate of the current over 24 hours in the residential substation. 
Table 3. Technical characteristics of the electrical substations.

\begin{tabular}{ccccccc}
\hline $\begin{array}{c}\text { Electrical } \\
\text { substations }\end{array}$ & Apparent Power & $\begin{array}{c}\text { Short-circuit } \\
\text { voltage }\end{array}$ & Coupling & $\begin{array}{c}\text { Primary voltage } \\
\text { (RMS) }\end{array}$ & $\begin{array}{c}\text { secondary voltage } \\
\text { (RMS) }\end{array}$ & $\begin{array}{c}\text { secondary current } \\
\text { (RMS) }\end{array}$ \\
\hline Domestic (Kalley-East) & $630 \mathrm{kVA}$ & $4 \%$ & Dyn11 & $20 \mathrm{kV}$ & $410 \mathrm{~V}$ & $909 \mathrm{~A}$ \\
Hospital (HNL) & $1000 \mathrm{kVA}$ & $5 \%$ & Dyn11 & $20 \mathrm{kV}$ & $400 \mathrm{~V}$ & $1443 \mathrm{~A}$ \\
Industrial (ORIBA) & $1260 \mathrm{kVA}$ & $5.5 \%$ & Dyn11 & $20 \mathrm{kV}$ & $410 \mathrm{~V}$ & $1306.3 \mathrm{~A}$ \\
\hline
\end{tabular}

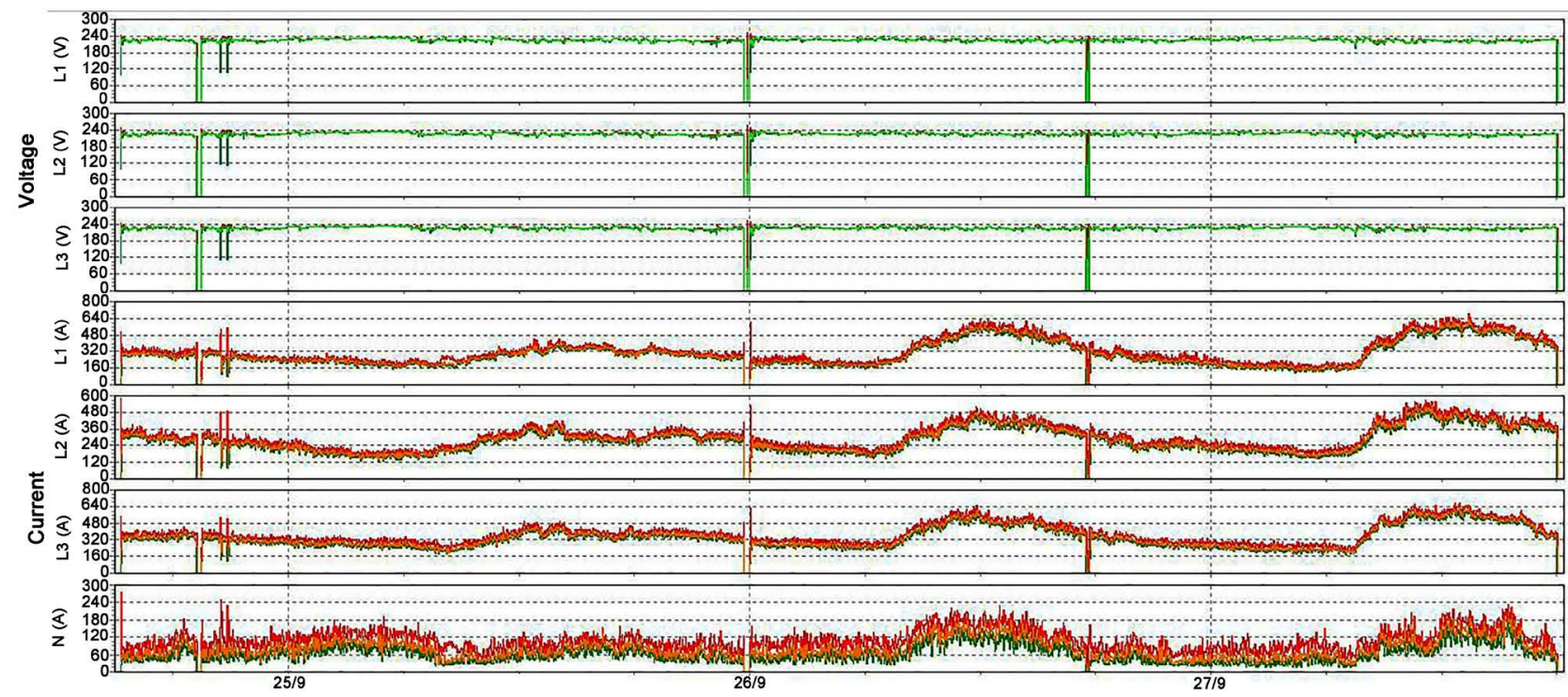

Figure 4. Recording view.

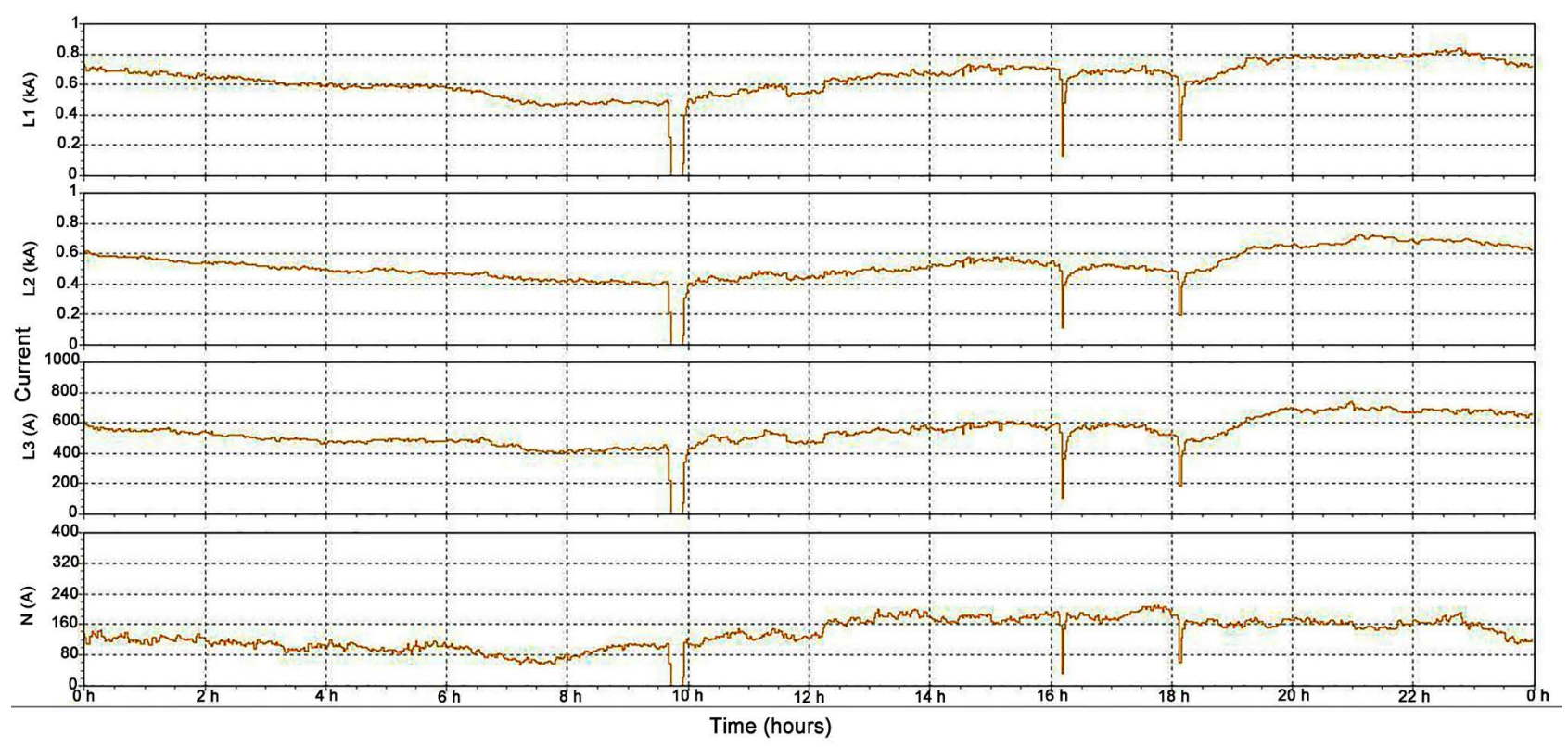

Figure 5. Evolution of the consumption in 24 hours on the residential substation.

Figure 7 shows the variation of the overall harmonic rate of 24 hours voltage in the home substation. 


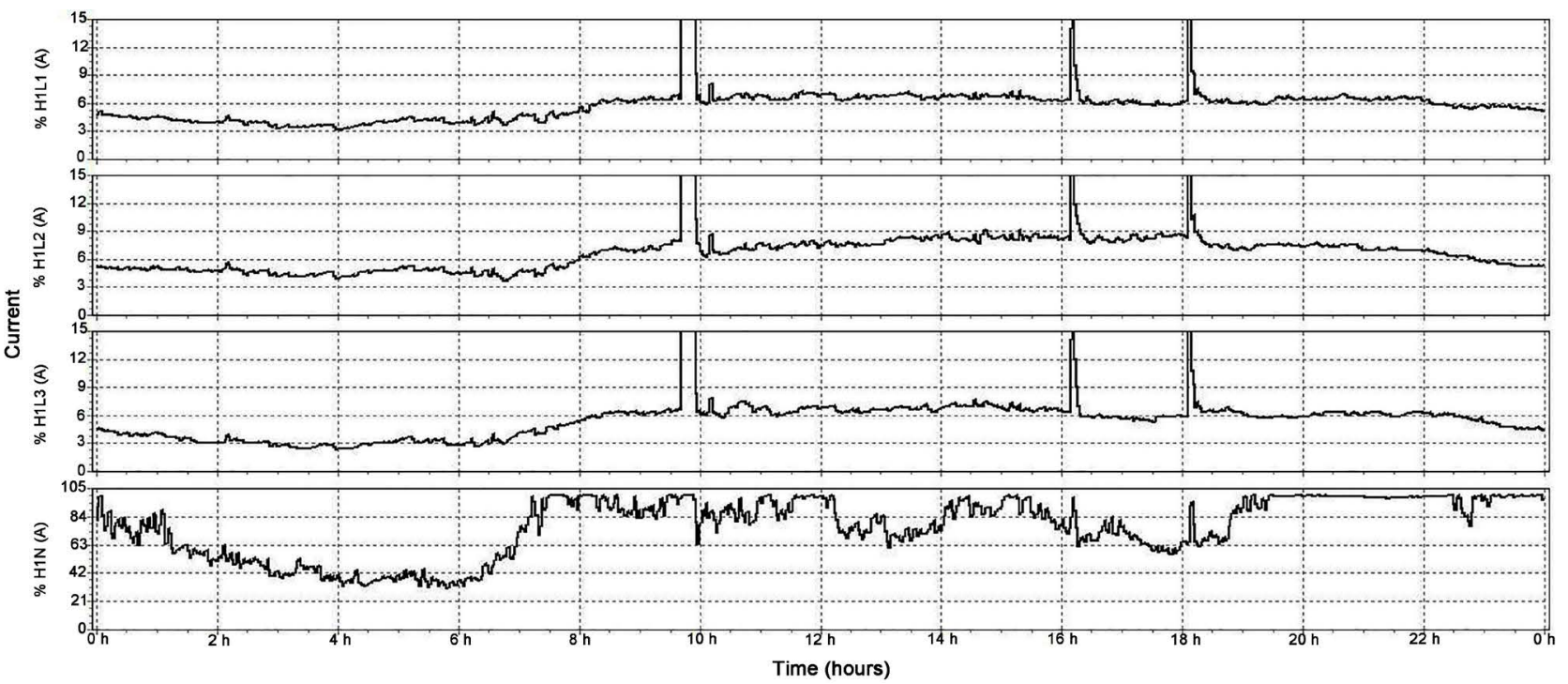

Figure 6. Variation of the overall harmonic rate of the current over 24 hours in the residential substation.

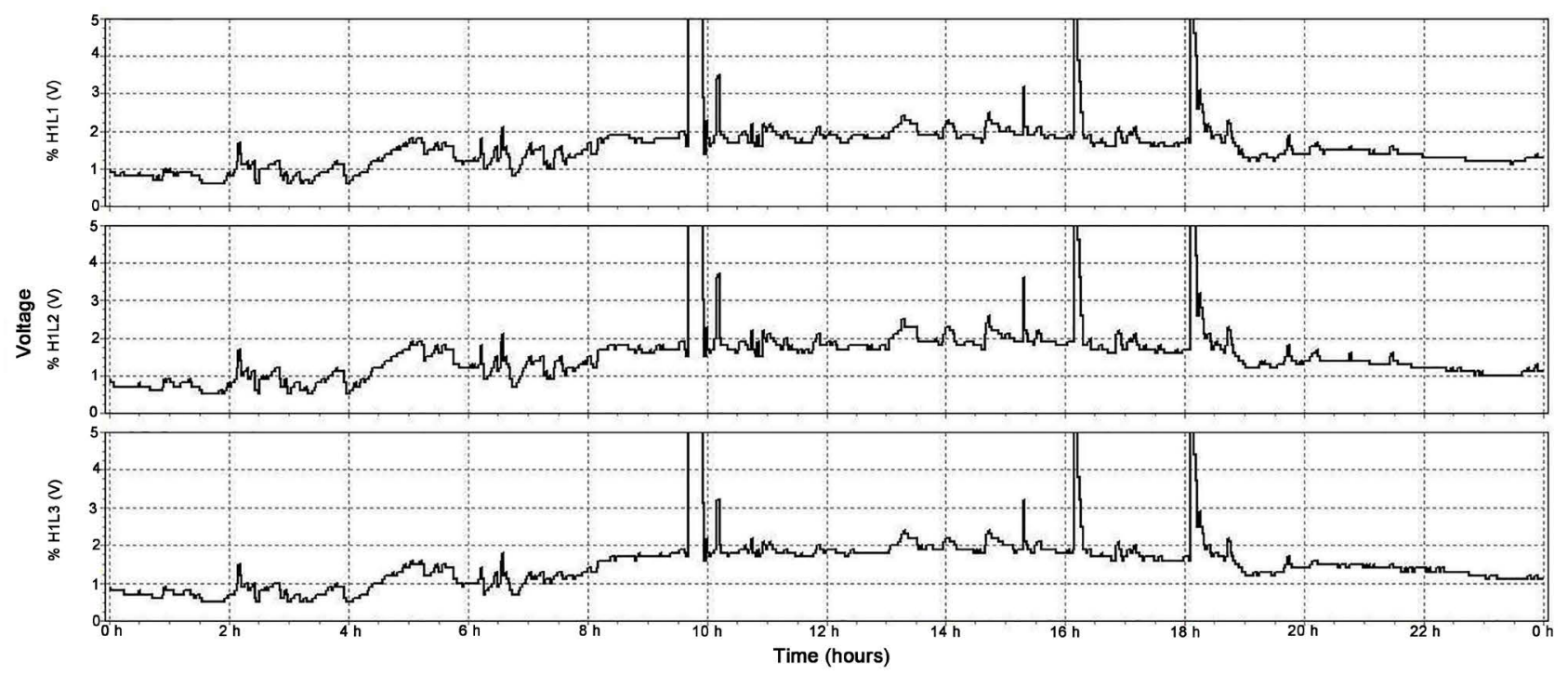

Figure 7. Variation of overall harmonic rate of 24 hours voltage in the home substation.

\subsubsection{Results of Hospital Site}

Figure 8 shows the evolution of the consumption in 24 hours in the hospital substation.

Figure 9 shows the variation of the overall harmonic rate of the current in 24 hours in the hospital substation.

Figure 10 describes the variation of the overall harmonic rate of the voltage in 24 hours in the hospital substation.

\subsubsection{Results of the Industrial Site}

Figure 11 shows the evolution of the current in 24 hours at the industrial substation.

Figure 12 relates the variation of the overall harmonic rate of the voltage in 24 hours at the industrial substation. 


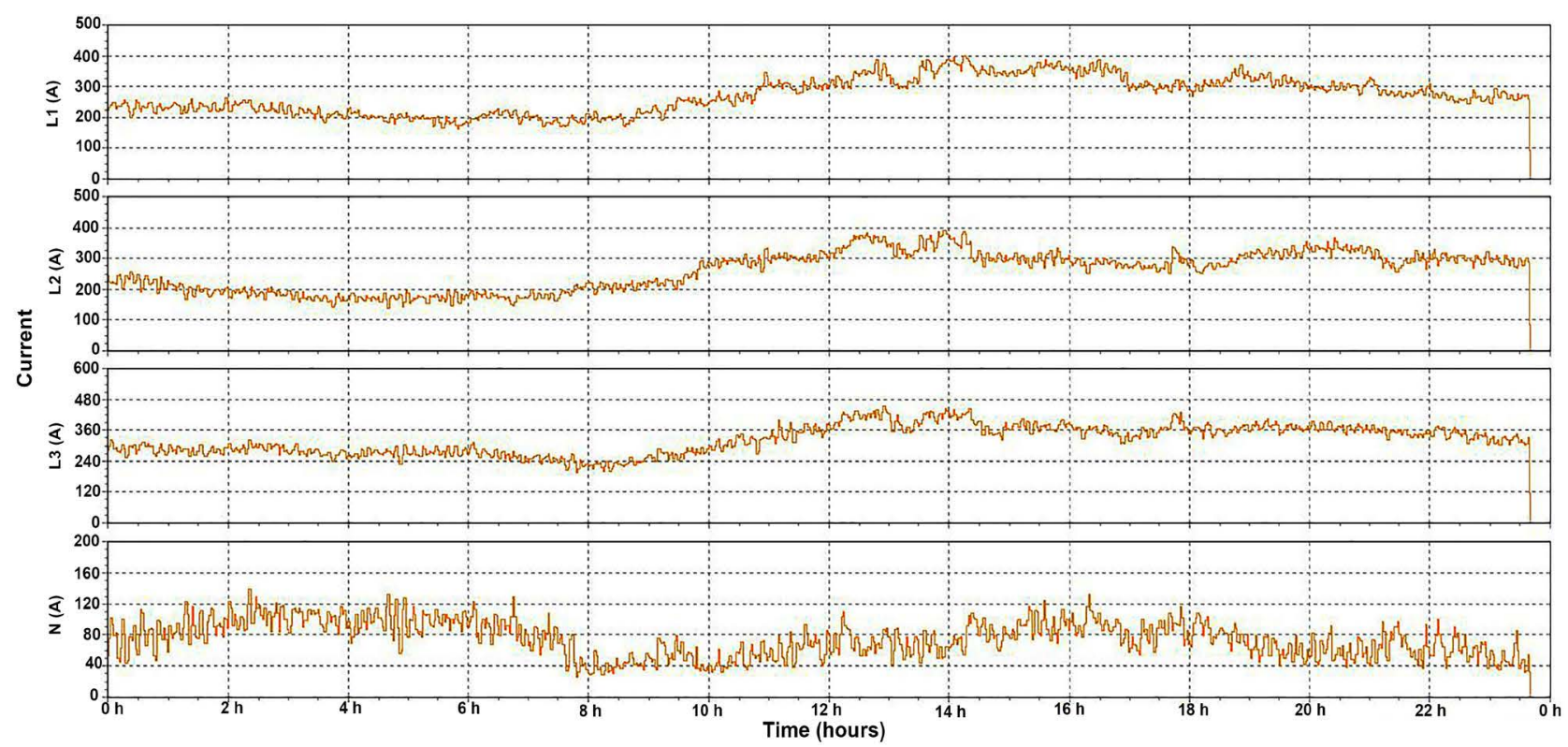

Figure 8. Evolution of the consumption in 24 hours on the hospital substation.

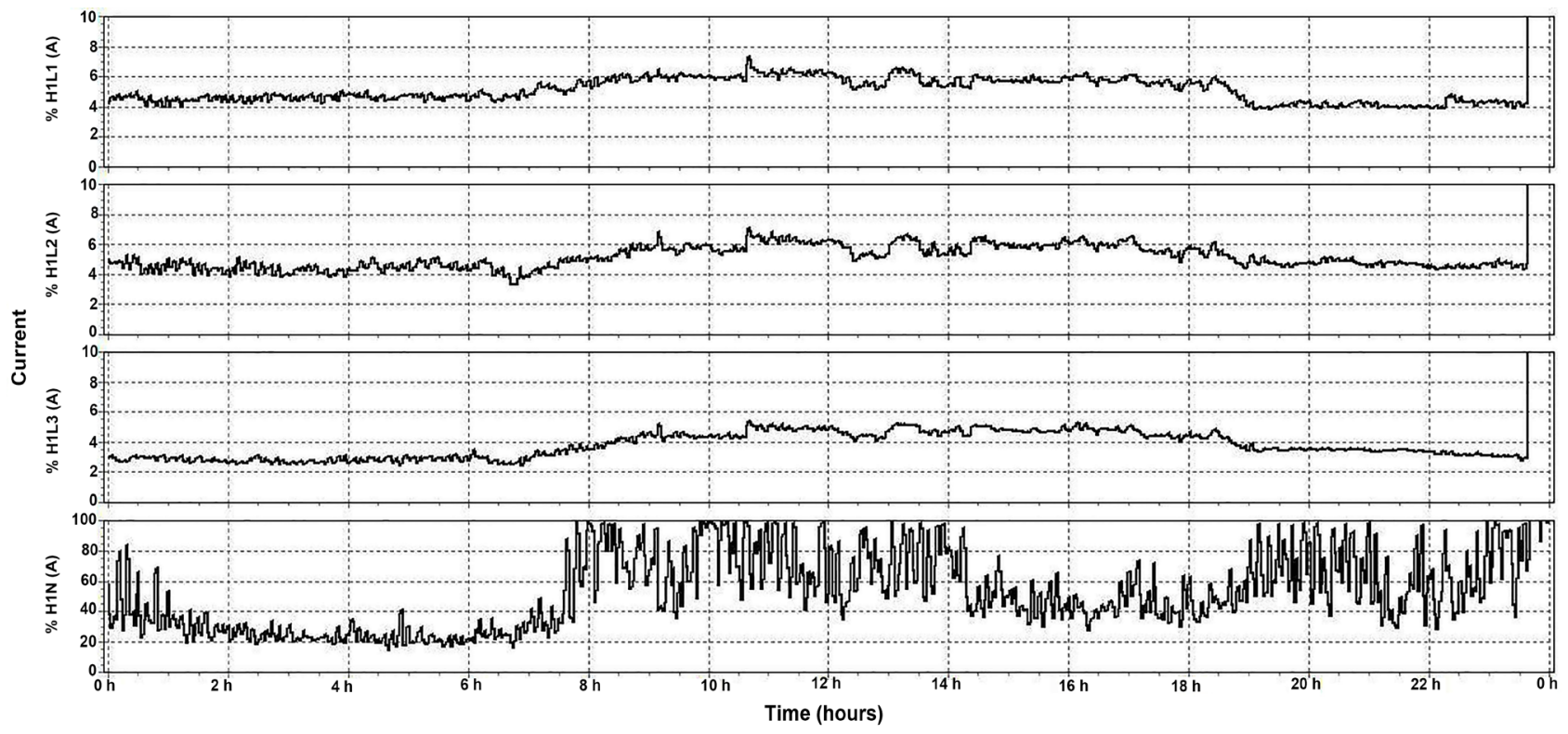

Figure 9. Variation of the overall harmonic rate of the current in 24 hours on the hospital substation.

Figure 13 relates the variation of the overall harmonic rate of the current in 24 hours at the industrial substation.

\subsection{Synthesis of the Results of the Three Sites}

Figures 5 through 13 allow synthesizing the results of the three substations in current and harmonic rates recorded on the three phases and the neutral. Table 4 and Table 5 show the RMS mean and maximum current values of the imbalance and the overall harmonic rates recorded during 24 hours at the three substations. 


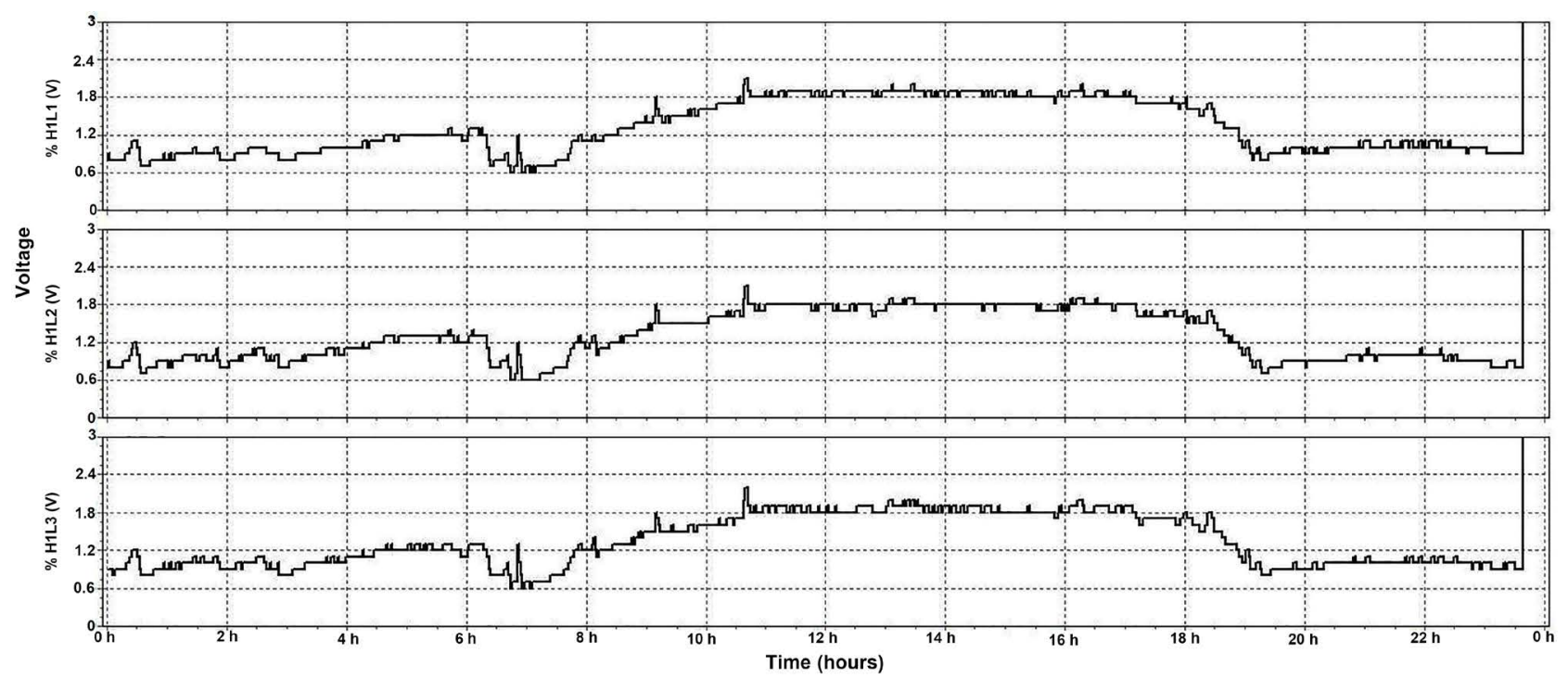

Figure 10. Variation of the overall harmonic rate of the voltage in 24 hours in the hospital substation.

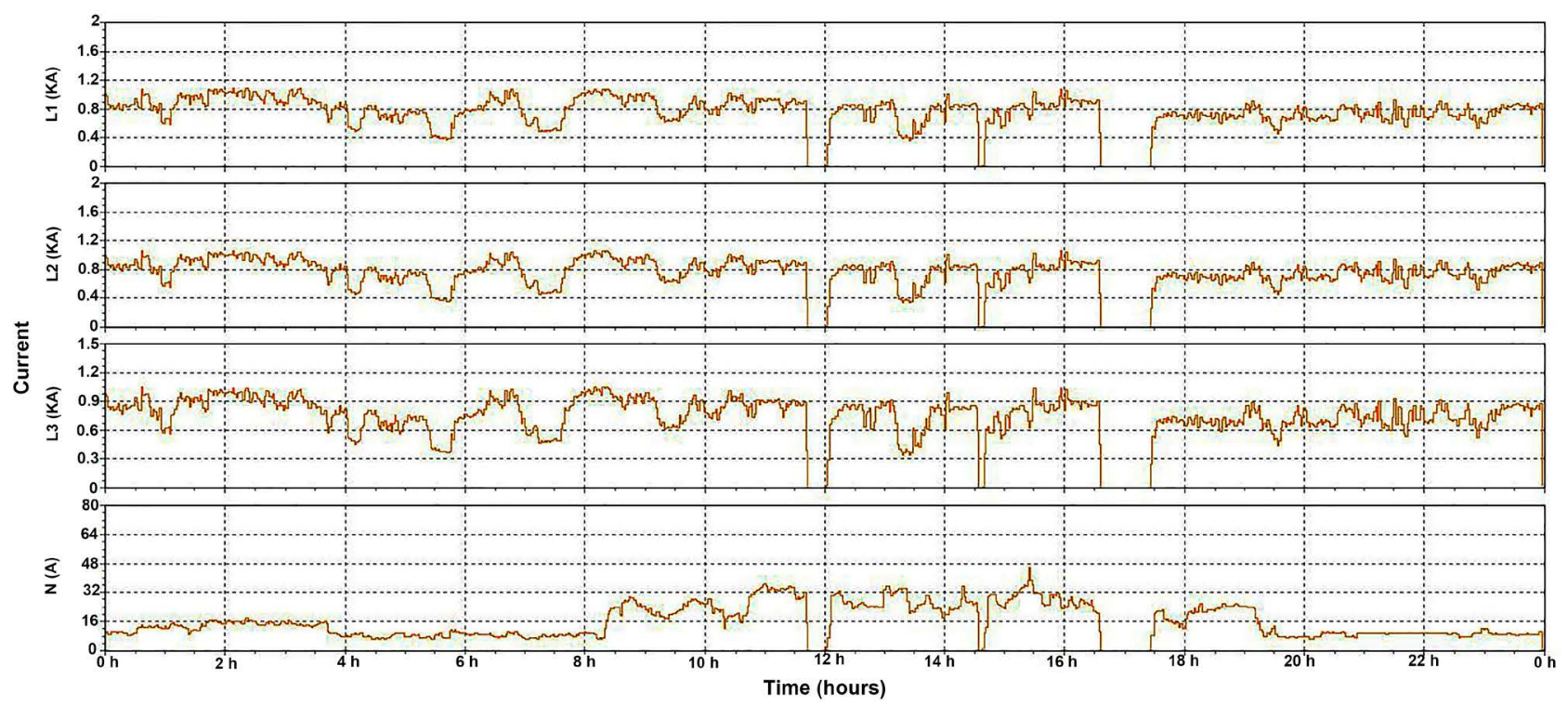

Figure 11. Evolution of the current in 24 hours on the industrial substation.

\subsection{Analysis and Interpretation of Results}

In order to remain faithful to the data collected, we have to process the data on a case-by-case basis, i.e., item by item. To do this, it is first necessary to exclude the phenomena during the cut-off period and to use the reference of IEEE 519-1992 to deduce the state of the network.

Thus, in the domestic substation, the harmonic voltage level is acceptable with a variation of $0.5 \%$ to $3.7 \%$ of mean distortion compared to $5 \%$ fixed by IEEE 519-1992. The results of the distortion rates in the active conductors (phases) ranges from $2.3 \%$ to $8.6 \%$. On the other hand, the overall harmonic rate is very significant (135.80 A that implies a lack of balance) in the neutral. On this site, the devices are in single-phase; among others are televisions, light bulbs, fans, 


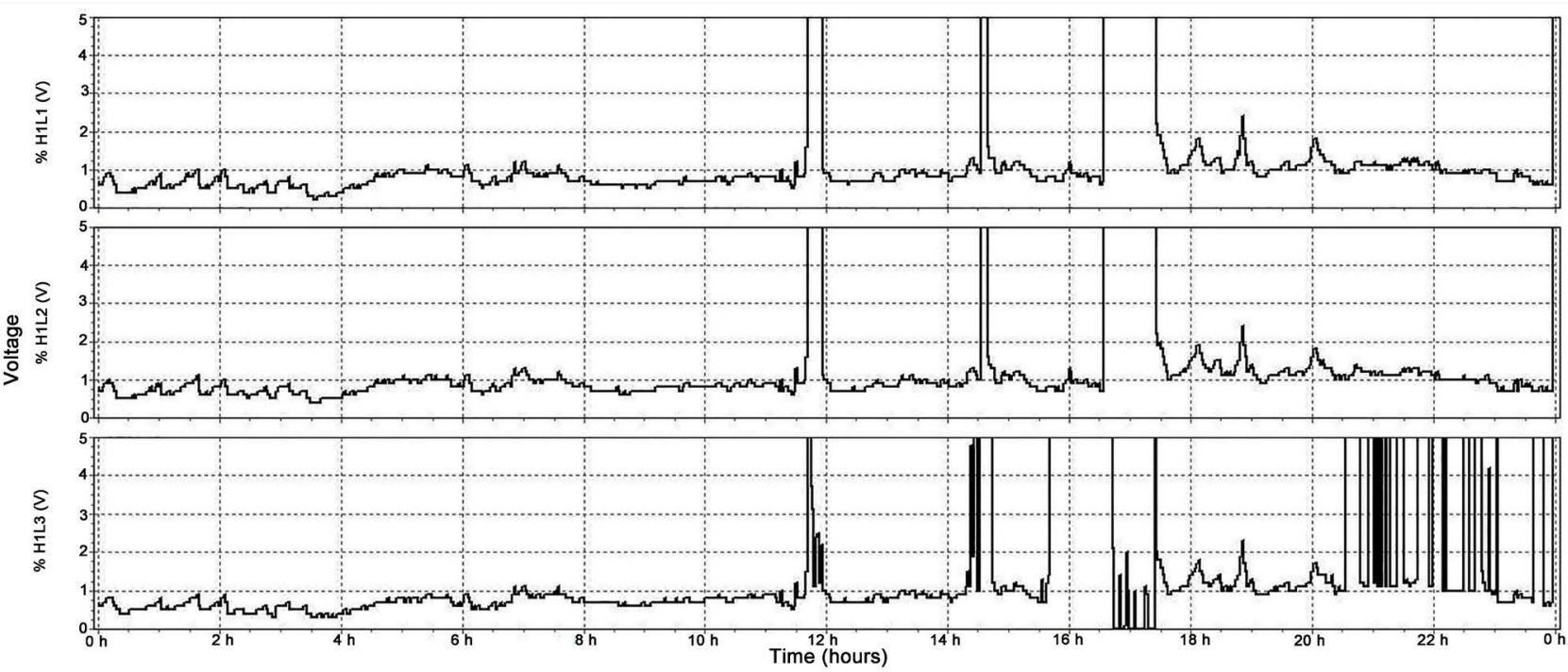

Figure 12. Variation of the overall harmonic rate of the voltage on 24 hours in the industrial substation.

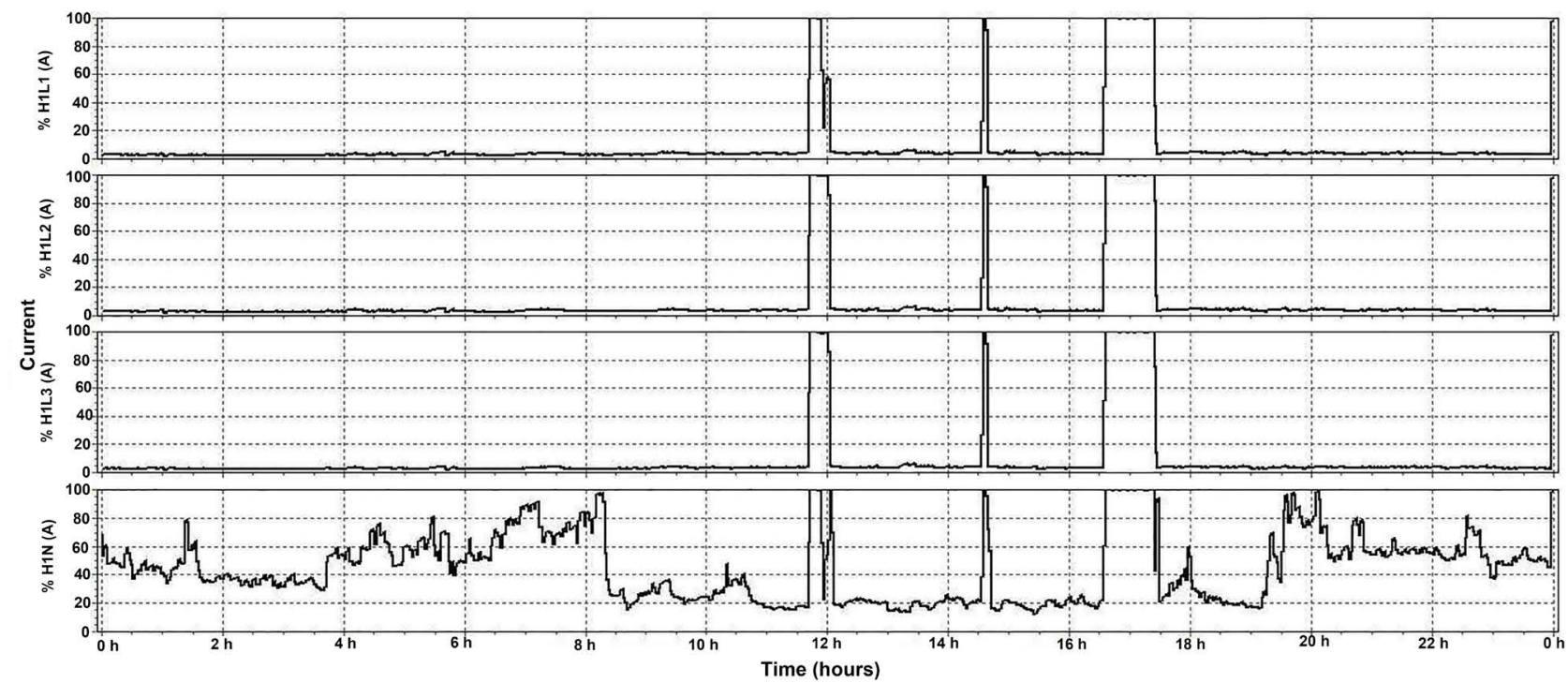

Figure 13. Variation of the overall harmonic rate of the current in 24 hours at the industrial substation.

phone chargers, etc. [6]. It should be noted that the variation of the harmonic rates is due to the variation of the loads which is explained by the non-linearity of loads and the daily activities of subscribers. Figures 5-7 show this variation on 24 hours period.

On the hospital site, this substation is designated as a special site according to the IEEE standard, and has set a maximum threshold of 3\%. This site is powered by a cabin station (1000 kVA). The devices and equipment identified are mostly single-phased (spectrophotometers, hematology equipment, biochemical automatons, dental chairs, dialysis machines, surgical lamps, air conditioners, fans etc). Here, in particular in Figure 9 and Figure 10, the investigation on the National Hospital of Lamorde site allowed us to record an average variation in the overall harmonic percentage in voltage of $0.5 \%$ to $2.2 \%$ and that of the current in 
Table 4. RMS and average maximum values of the current in the neutral in the 24 hours on the electrical substations.

\begin{tabular}{ccc}
\hline Substations & Value & IN (A) \\
\hline \multirow{2}{*}{ Domestic } & Mean & 135.80 \\
& Maximum & 210.41 \\
Hospital & Mean & 74.21 \\
& Maximum & 138.00 \\
Industrial & Mean & 15.75 \\
& Maximum & 45.55 \\
\hline
\end{tabular}

Table 5. Overall harmonic distortion rate recorded during 24 hours.

\begin{tabular}{cccc}
\hline Substation & THDv (\%) & THDA (\%) & THDn (\%) \\
\hline Domestic & $(0.5$ to 3.7$)$ & $(2.3$ to 8.6$)$ & $(30.3$ to 99.9$)$ \\
Hospital & $(0.5$ to 2.2$)$ & $(2.4$ to 7.3$)$ & $(14.5$ to 99.5$)$ \\
Industrial & $(0.2$ to 2.4$)$ & 1.6 to 6.5$)$ & $(12.3$ to 99.1$)$ \\
\hline
\end{tabular}

the phases between $2.4 \%$ and $7.3 \%$ followed by $16 \%$ to $99.5 \%$ in the neutral. This high rate is due to the lack of a balanced current (138 A in the neutral). The behavior of loads on this item is shown in Figure 8:

- From 7:30 AM to 2:00 PM: we observe a growth of the graph. Because in the hospital most of medical check-ups (using laboratory, imaging equipment and others) are usually carried out by this time followed by the use of the air conditioning later.

- From 2:00 PM to 6:30 PM: we have a stable trend. From this time most of consultation equipment are shut down (except for emergency) at the closing of consultation room.

- From 6:00 PM to 7:30 AM: we have a declining trend. This is due to the closing of administration and other services.

ORIBA substation is of larger size $(1260 \mathrm{kVA})$ compared to the other two. It supplies mostly large three-phase apparatuses, for example $67 \mathrm{~A}$ shrink wrapper, 120 A chiller trane, 120 A blowers, etc. With such a system, it is evident that a THDv of $0.5 \%$ to $2.4 \%$ and a THDA of $1.6 \%$ to $6.5 \%$ are recorded [15], except for the THDn which is between $12.3 \%$ and $99.1 \%$. In the industrial zone, consumption is stable according to two regimes, the production period and the period of stoppage. This is exactly what the curve of variation of the current and harmonic rates describes. It is worth noting that the occurrence of voltage instability on the phase at 15:41 caused the same behavior on the THD3 (V). This instability is due to the connection to the terminal block of phase 3 , which leads to consumption at the same time and on the same line.

\section{Conclusions}

The investigation on the harmonics at the residential, hospital and industrial 
substations shows the presence of harmonics on the electricity distribution network of the Niamey city. The level of voltage distortion in each station is acceptable in accordance with the contractual values set by the standards.

The evolution of the consumption is identical to that of the overall harmonic rates, this justifies that the loads connected to the substations are non-linear. We note that the domestic and hospital posts are subject to the same variation (growth, stability and decrease).

Nevertheless, we observe a critical level of the overall harmonic rate in the neutral at all sites. This is explained by the appearance of the large current in the neutral (imbalance), especially at the domestic station of about $210.41 \mathrm{~A}$ and the hospital post with a current on the neutral of $138 \mathrm{~A}$. Such an imbalance results in a heating up of the neutral conductor, leading to the losses of the transformer substations.

The study allowed us to highlight that the troughs of tensions cause a high overall harmonic rate and consequently losses of both the supplier and the customers. As a result, energy producers must reduce the voltage drop time.

However, for an accompaniment in the availability of high-quality electricity in Niger and as the use of devices generating harmonics grow daily, it would be wise to provide a solution to attenuate the presence of harmonics on these substations. Therefore, in order to have a global control over the quality of the electrical energy that Niger National Electricity Company distributes, we intend in the future to make this study over a long period and continuously, with all the electrical substations in Niamey city.

\section{References}

[1] Rafanotsimiva, L.F. (2013) Study of Nonlinear Controls for Electrical Networks: Application to a SMIB System. Ph.D. from the University of Antseranana, Madagascar.

[2] PANEE, PEEC (2015) Energy Information System (EIS), Directorate of Energy, Ministry of Energy and Oil, Niamey-Niger.

[3] Activity Report - NIGELEC (2015) Final Report of the Resettlement Action Plan of the Reinforcement and Extension Project for the Electrical Networks of the Cities of Niamey, Dosso, Maradi, Zinder, Tahoua, Agadez and Tillabery. NIGELEC, Niamey-Niger.

[4] Frelin, W. (2009) Impact of Harmonic Pollution on Network Equipment. Ph.D. Dissertation, University of Paris Sud XI.

[5] Berthet, L., Boudou, D. and Mamo, X. (2001) First Results of the Measurement Campaign of Harmonics on French Low-Voltage Networks. 16th International Conference and Exhibition on Electricity Distribution, Contributions. CIRED, IEE Conf. Publ, No. 482, 199-204.

[6] Almaita, E. (2016) Harmonic Assessment in Jordanian Low-Voltage Electrical Power Grid. Recent Advances in Energy and Environmental and Biological Sciences, Series 46. Proceedings of the 5 th International Conference on Energy Systems, Environment, Entrepreneurship and Innovation (ICESEEI, 16), 216-220.

[7] Akagi, H. (2006) Modern Active Filters and Traditional Passive Filters. Bulletin of the Polish Academy of Sciences Technical Sciences, 3, 255-269. 
[8] Jutten, C. (2009) Theory of the Signal. Polytech, Grenoble.

[9] Bellanger, M. (2016) Digital Signal Processing. 8th Edition, Dunod, Paris.

[10] Dutoit, T. (2016) Frequency Analysis of Signals and Digital Systems. Faculties Polytechnic of Mons, Belgium.

[11] Felice, E. and Revilla, P. (2009) Quality of Electrical Networks and Energy Efficiency. Dunod, Paris.

[12] Collombet, C., Lupin, J.M. and Schonek, J. (1999) Harmonic Disturbance in Polluted Networks, and Their Treatment. Schneider Electric Technical Manual, 152, 14.

[13] De la Rosa, F. (2006) Harmonics and Power Systems. CRC Press, Boca Raton. https://doi.org/10.1201/9781420004519

[14] IEEE Standards Association (2014) IEEE Recommended Practice and Requirements for Harmonic Control in Electric Power Systems. Revision of IEEE Std 519-1992.

[15] Oueidat, M. (2009) Electromagnetic Disturbances in the Lebanese and Syrian Industrial Sector. 5 th International Conference: Sciences of Electronic Technologies of Information and Telecommunications, 5. 